\title{
Compensation Mechanisms when Interacting with Learning Aids
}

\author{
Geraldine Clarebout(Correspondingauthor) \\ Centre for Instructional Psychology and Technology, KatholiekeUniversiteit Leuven \\ Dekenstraat 2 box 3773 - 3000 Leuven, Belgium \\ E-mail: geraldine.clarebout@ped.kuleuven.be \\ Holger Horz \\ Goethe University Frankfurt am Main \\ Mertonstrasse17, 60054 Frankfurt am Main, Germany \\ E-mail: Horz@psych.uni-frankfurt.de \\ Jan Elen \\ Centre forInstructionalPsychologyand Technology, Katholieke Universiteit Leuven \\ Dekenstraat 2 box 3773 - 3000 Leuven, Belgium \\ E-mail: jan.elen@ped.kuleuven.be \\ Wolfgang Schnotz \\ Departement of Educational and General Psychology, University of Koblenz-Landau \\ Thomas Nast Strasse 44, 76829Landau, Germany \\ E-mail: Schnotz@uni-landau.de
}

Received: February24, $2011 \quad$ Accepted: March25, 2011 doi:10.5430/wje.v1n1p119

This research is co-financed by the Flemish National Science Foundation (Project No. G0480.09) and was made possible due to an internationalization grant of the Humanities and Social Sciences Group of the KatholiekeUniversiteit Leuven.

\begin{abstract}
Learning environments commonly offer aids to address learners' lack of knowledge or skills. However, learners are not or sub-optimally using these aids when these are non-embedded or segregated (Aleven, Stahl, Schworm, Fischer, \& Wallace, 2003; Clarebout\& Elen, 2006). This lack of optimal usage has been related to variables as self-regulation and prior knowledge (e.g., Hill \&Hannafin, 2001; Land, 2000). Given this relationshipbetween learning aid usage and prior knowledge and self-regulation, we focused in this study upon the interaction between these two learner variables and the embeddedness of learning aids (embedded - segregated). Fifty-seven university students randomly assigned to two conditions participated. Results indicate that segregating learning aids is beneficial for learners with high prior knowledge and low self-regulation skills, as well as for learners with low prior knowledge and high self-regulation skills. This result reveals the compensatory relationship between domain-specific prior knowledge and domain-general regulation skills.
\end{abstract}

Keywords: Learning aids, Self-regulation, Prior knowledge, Instructional design

\section{Introduction}

Learning environments often provide a large amount of control to the learners, including control over the use of learning aids. These learning aids comprise all supportive elements in a learning environment that may compensate for learners' lack of prior knowledge, cognitive and metacognitive skills. However, research reveals that the use of these learning aids is often problematic: learners do not, or sub-optimally, utilize the different learning aids offered to them (Aleven, Stahl, 
Schworm, Fischer, \& Wallace, 2003; Clarebout\& Elen, 2006; Horz, Winter, \& Fries, 2009). This finding corresponds to the findings of Perkins (1985), namely that learners do not automatically take up the learning opportunities (in this case. learning aids) offered to them. While one could argue from an instructional design perspective then not to provide learner control on the use of learning aids, this seems to be a more complex issue.

Different arguments can be put forward over whether to provide this control to learners: First, providing learner control is likely to increase learners' motivation due to a perceived higher self-efficacy during learning and hence may lead to increased learning gains (Williams, 1996). A second argument is that learner control, provides an opportunity to create an adaptive learning environment,in which learners only receive the amount of support they actually need. The latter argument assumes that learners can decide for themselves which elements in a learner environment are useful (or not) to their learning, and consequently use the learning aids that compensate for a self-identified deficiency in knowledge or skills. Third, and perhaps a very simple reason to provide control to learners, is that the designer is not $100 \%$ sure of the functionality of the elements (including learning aids) in a learning environment. It may be unclear, for instance, whether the use of the learning aid is actually beneficial to learning (Elen \&Clarebout, 2006). Additionally, even when embedding a potentially functional learning aid, it is not guaranteed that learners will use it in an optimal or adequate way. For example, Greene and Land (2000) revealed that an obligatory reflection aid was mainly used for listing the websites students had visited during their learning task, rather than for writing their reflections on their problem solving process. A fourth reason, and probably a more common one to provide learning control over learning aids than the third, is that most learning environments are not designed for one particular learner, but for a group of learners in which some may require additional support, and others not. When the learning aids are embedded, all students will use them. Providing control to the learner eradicates the possibility that those learners who do not need the learning aids may be hampered in such learning environments. Too much support may also be detrimental (Clark, 1990). A reason for the hampering effect of learning aids upon some learners may be that the content provided by the learning aids is redundant tothe learners' prior knowledge. A well-studied illustration of this kind of information redundancy is known as the expertise reversal effect (Kalyuga, Chandler, \&Sweller, 2000). If learners have high prior knowledge, they frequently do not require the additional information provided by learning aids. In this case, including learning aids means adding unneeded information. The processing of this unneeded information requires additional cognitive processes devoid of any further learning outcomes; thus, the learner loses time and expends mental effort processing redundant information provided by learning aids. Therefore, it is reasonable to predict that learners with higher expertise will perform better without learning aids, while those with lower expertise will perform better with embedded learning aids. This expertise reversal effect shows the complex relationship between learner variables and learning aid usage.

Evidence on the interaction between prior knowledge and specific instructional interventions can, for instance, be found in research on the effect of text coherence, concept maps, or text structure. McNamara, Kintsch, Butler-Songer and Kintsch (1996) found that low knowledge readers learn more from a highly-coherent text, while high knowledge learners benefit more from a low-coherent text. Gurlitt and Renkl's study (2008) reveals an interaction effect between prior knowledge and the type of prior knowledge activation a concept map provided. Students with a greater learning experience (from a higher educational level) benefited more from low-coherent prior knowledge activation, while participants with lesser learning experiences (lower educational level) benefited more from highly-coherent prior knowledge activation. Similarly, Potelle and Rouet (2003) showed that the kind of additional structure (hierarchical, network or alphabetical) in a hypertext has positive effects for low prior knowledge learners while no effect is found for high prior knowledge learners. Interestingly, Schnotz and Heiss (2009) reveal that high prior knowledge learners benefit more from adequate scaffold use in a hypertext environment than low prior knowledge students. The scaffolds in this study were semantic scaffolds including an epitome as pre-organizer, learning objectives and problem-oriented questions. Similar results are retrieved in an experiment with a complex authentic learning environment (Horz et al., 2009): learners with lower prior knowledge are not able to use learning aids sufficiently, in contrast to learners with higher prior knowledge. Here, additional learning aids led to too high cognitive demands for learners with lower prior knowledge. It appears that in complex learning environments, learners with low prior knowledge are unable to cope with the additional processing the scaffolds demand. However, it should be noted that the types of learning aids focused upon differ between the studies mentioned above, and that some studies reveal that the nature of the learning aid itself may also influence the usage of learning aids (e.g., Martens, Valcke, \&Portier, 1998).

In sum, the interaction between learning aid usage and prior knowledge seems to be complex. On the one hand, learning aid usage may differ dependent on students' prior knowledge, and may even cause a mathemathantic effect. On the other hand, it seems that -at least in a complex learning environment- students need to have attained a certain amount of prior knowledge to allow them to use the provided learning aids adequately.

Not only has prior knowledge been identified as an important variable in learning aid usage, but also self-regulation. 
Numerous authors (e.g., Greene \&Azevedo, 2007; Horz et al., 2009; Winne\& Jamieson-Noel, 2002) indicate that self-regulation is a variable that determines to what extent learners are capable of monitoring and controlling their learning process. This also includes the capability to determine when they need support, i.e. when the use of a learning aid would be helpful. A number of studies consequently addressed self-regulation as the characteristic to be supported (e.g. Narciss, Proske, \&Koerndle, 2008; Winters, Greene, \&Costich, 2008). The relationship between self-regulation and the use of learning aids, however, has not yet been studied. In other words, while self-regulation is often mentioned as a variable explaining the (lack of) use of learning aids, and that the support offered by the learning aids is often directed so as to compensate for a lack of self-regulation, the relationship itself has hardly been studied.

Moreover, the relationship between prior knowledge and self-regulation is not clearly clarified in literature. When discussing the use of specific affordances in learning environments, prior knowledge and self-regulation seem to be highly interrelated, rather than clearly distinguishable concepts. For instance, Shapiro (2008) indicates that a hypermedia system encourages learners to exercise their self-regulation skills, but that low prior knowledge students have difficulties in meeting the learning goals unless structure is imposed. Shapiro concludes that the effectiveness of the structure is mediated by learners' prior knowledge. It appears that in Shapiro's study self-regulation and prior knowledge are almost used as interchangeable concepts.

The literature cited above clearly indicates that prior knowledge and self-regulation may interact with the use ofelements of a learning environment. However, it remains unclear as to how learning aids should be offered to learners. While Azevedo and Jacobson (2008) conclude in their special issue that when and how to scaffold relates to whether the scaffolding is always, selectively or adaptively available, no indication is given as to what would be the best decision for a designer. Should we induce learners to use learning aids (scaffolds) and risk that high prior knowledge and high self-regulation learners are hampered in their learning process, or is it more advisable to leave the option to the learner, and risk that low prior knowledge and low self-regulation learners do not get the support they require?

This contribution aims to enhance our understanding of the interrelationships between prior knowledge, self-regulation and the use of learning aids in low-complexity learning environments (contrary to the complex learning environment in the 2009 study of Schnotz and Heiss, for instance). We hypothesize that for high prior knowledge and highly self-regulated learners, embedding the learning aids - and hence inducing learners to use the devices - will not contribute to, or even hamper, their learning, whereas for low self-regulated and low prior knowledge students, not embedding the support device - and hence leaving the decision of use to the learners - will negatively affect their learning. Consequently, this study aims to reveal interaction effects; rather than main effects.

\section{Method}

\subsection{Participants}

Participants were 57 students from a German university, randomly assigned to two conditions. On average participants were 22.45 years old (sd $=3.70$ ), and were mainly psychology and educational sciences students, recruited through flyers in the university buildings. Thirteenmale and 47 female students participated. Students received either 10 Euros for participation or a study related credit.

\subsection{Design, Instrumentation and Procedure}

Acomputer based learning environment was designed to test our hypotheses. The learning environment consisted of a scientific text on obesity (translated from Dutch to German: Nederkoorn, Guerrieri, \& Jansen, 2006) presented on a computer screen. Three learning aids were integrated in the learning environment in the EA (embedded aids) condition, and three aids were added to the environment in the SA(segregated aids)condition. These aids all helped students with the interpretation of graphics in the text. In the EAcondition,all students received additional information on the interpretation of the graphic, while in the SAcondition students had to actively request this information by clicking a button. This button gave access to the same information as in the EA-condition.The learning aid explained a specific graphic by pointing to relevant points and by adding text boxes with an interpretation for these relevant points (Figure $1)$.

< Figure 1 about here $>$

Additionally, general information (not specified to the graphic at hand) on how to interpret graphics was given. It was opted to include only one type of learning aid to avoid effects caused by the type of aid present.

Independent variables were condition, prior knowledge and self-regulation. Prior knowledge was measured with a pre-test. This test consisted of 10 items (e.g., What does inhibitory control mean?) constructed by two researchers and employed in previous studies (Clarebout\& Elen, 2009). 
In order to group students by high and low prior knowledge, we relied upon the four items relating to interpreting graphics from the pre-test, since this is the knowledge that the aids compensate for. Students were grouped in high and low prior graph knowledge groups separated by the $50^{\text {th }}$ percentile score.

Self-regulation was measured through the LIST-questionnaire (Wild, 2000; Wild \&Schiefele, 1994). All selected items $(\mathrm{N}=48)$ from this questionnaire are applicable to studying learning materials individually, which was the experimental task (e.g., 'I make a list of subject specific expressions and difficult words', 'The materials I just read are the starting point for my own thoughts'). Items that were left out related to discussing study material with others or to the context (e.g., 'In order to study I remain in the same place'), since this was not applicable to the task participants were required to undertake. This meant that (a) the entire organization and elaboration scales were used, (b) one item was dropped from the critical thinking and memorizing scales ('I read my notes regularly'), (c) two items were dropped from the metacognitive strategies scale (e.g., 'I fix on the beforehand how far I should come with studying the learning material'); and (d) two items of the effort scale were included. Students responded to these statements by indicating to what extent the statement applied to them on a Likert-type scale from 1 (totally applicable) to 6 (not at all applicable). To group learners into high and low self-regulators, we classified each learner for each scale based around the $50^{\text {th }}$ percentile score. Students were either identified as below the $50^{\text {th }}$ percentile or above for each scale. In order to be classified as high self-regulators, learners should have at least scored above the $50^{\text {th }}$ percentile for three scales out of six. Otherwise, they were classified as low self-regulators.

The dependent variable was learning gainsmeasured through the subtraction of the pre-test score from the post-test score. The post-test itself consisted of 15 questions and was also constructed by two researchers and pre-tested in previous studies (Clarebout\& Elen, 2009).

The following procedure was used: Participants entered the computer room in groups of eight. They were asked to sit in front of a computer and were welcomed. Students were then asked to $\log$ in to the computer and to read a short newspaper article on obesity to activate their prior knowledge. After that, the pre-test and the LIST-questionnaire were administered. Next, students had 30 minutes to read the text on obesity after which they received the post-test. In total the session took 90 minutes.

To analyse the results, first reliability analyses were performed on the different instruments. For the pre- and post-test a Kruder-Richardson 20 was calculated,given that the items were scored either as correct(1) or incorrect (0), and no equal difficulty level was assumed between the items (Fraenkel\&Wallen, 2003). For the LIST-questionnaire, the Cronbach alpha values were calculated for the different scales. Second, an ANOVA was performed to see whether the two groups were equal for prior (graph) knowledge. Next, we performed a 2x2x2 ANOVA with prior graph knowledge (high-low), self-regulation (high-low) and condition (SA-EA) as independent variables and learning gains as dependent variables. For all performed ANOVAs, normality was checked of the dependent variable (skewness and Kurtosis), and Levene's test was performed to check for equality of the error variances.

\section{Results}

Reliability for the pre- and post-test was respectively; K-R20 $=.71$ and .77 . For the different scales of the LIST-questionnaire Cronbach's alphas between .73 and .84 were obtained. Consequently, all scales were included to classify students as high or low self-regulators.

All continuous variables were normally distributed (skewness and Kurtosis $<1.00$ ), and the Levene's tests showed for none of the performed ANOVA's a problem with unequal error variances ( $\mathrm{p}>.05)$.

No differences were found between the two groups for prior graph knowledge, $F(1,59)=.97$; $\mathrm{p}=.76$, nor for overall prior knowledge, $F(1,59)=.08, p=.76$.

Although the main interest of this study is situated on the level of the interaction effect, the main effects are first briefly discussed.

The results reveal a large main effect of prior graphknowledge, $F(1,56)=8.29, \mathrm{p}<.01, \eta^{2}=.15$ and condition $F(1,55)=7.63$, $p<.01, \eta^{2}=.14$, and a moderate main effect of self-regulation, $F(1,55)=3.98, p=.05, \eta^{2}=.08$ on learning outcomes. Results (Table 1) show that overall low prior knowledge participants had significantly larger learning gains than participants with high prior knowledge. A similar difference was found for self-regulation: participants with low self-regulation showed significant higher learning gains than participants with high self-regulation. With respect to condition, it was found that overall participants in the SA-condition showed larger learning gains than participants in the EA-condition.

< Table 1 about here> 
More pertinent to our research question are the retrieved interaction effects. A first large interaction effect was found between self-regulation and prior graph knowledge, $F(1,55)=7.21, p=.01, \eta^{2}=.13$. Participants with low self-regulation and high prior graph knowledge have significant lower learning gains $(M=-.18, s d=3.74)$ compared to participants with low self-regulation and low prior graph knowledge $(M=2.63$, sd=3.08).It even seems that the low self-regulation and high prior graph knowledge learners do not show any learning gains. No significant difference was found for participants with high self-regulation and low or high prior graph knowledge. Both of these groups differed significantly from the high prior knowledge and low self-regulation group (Figure 2).

\section{$<$ Figure 2 about here $>$}

No significant two-way interaction effect was found between prior graph knowledge and condition, or between self-regulation and condition.

However, a significant three-way interaction effect was found between self-regulation, prior graph knowledge and condition upon learning gains, $F(1,55)=6.70, p=.01, \eta^{2}=.12$. The results reveal that participants with low prior knowledge and high self-regulation have significant higher learning gains in the SA-condition $(M=3.50, s d=1.78)$ than in the EA-condition $(M=.63$, sd=2.56). Similarly, participants with high prior knowledge and low self-regulation perform significantly worse in the EA-condition $(M=-5.75$, $s d=5.75)$, than in the SA-condition $(M=1.06$, $s d=2.48)$. In this scenario, integration of the aids led to detrimental effects on learning. For participants with high prior knowledge and high self-regulation, or with low prior knowledge and low self-regulation, the two conditions lead to similar learning gains (Figures 3\&4).

\section{$<$ Figures 3\&4 about here $>$}

\section{Discussion and Conclusion}

This study addressed the effect of integrating learning aids into a learning environment upon learning gains. Self-regulation and prior knowledge were considered as variables that may cause an interaction effect. The results revealed some main effect of self-regulation, condition and prior graph knowledge. Overall, such a learning environment was found to be most beneficial for low prior knowledge and low self-regulation learners. Concerning the main effect of condition it was found that segregated aids led to higher learning gains. This may be explained by the way in which students used the learning aids. A previous study (Clarebout, Horz, Schnotz \& Elen, 2010) revealed that students who had control over the use of learning aids used them less frequently, but when they used the aids, they used them more adequately: they spent more time on processing the information offered by the learning aid. It seems that perhaps providing students with the illusion of control would be the best solution for low prior knowledge or low self-regulation learners. This would ensure these learners use the learning aids, but that they engage more in processing the information conveyed when using the aids, due to the feeling of control they have.

But the most interesting result, however, was the three-way interaction between prior graph knowledge, self-regulation and condition. Apparently, an environment with segregated aids is better than an environment with integrated aids for low prior knowledge learners with high self-regulation, and for high prior knowledge students with low self-regulation. It seems that in this interaction effect prior knowledge and self-regulation compensate for one another. Interestingly, nodifference between the two environments was found for students with high prior knowledge and high self-regulation skills, or for students with low prior knowledge and low self-regulation skills. Regarding the first group of learners, one could hypothesize that they have the skills to flexibly adapt to the environment, and that redundant information (integrated aids) can be ignored or processed in an efficient way, at least in a non-complex learning environment.Based on these results, it may be wondered whether an expertise reversal effect would be found for learners with high prior knowledge and high self-regulation skills.

However, more puzzling is the result found for low prior knowledge students that are also low self-regulators. One would expect that these students require the aids the most,and that they need to be guided, based upon the assumption that they are not very good at determining when they need help.The results here do not support this. An explanation for these findings could be that the quality of learning aid usage plays an important role (Clarebout et al., 2010). It can be argued thatmost likely learners with low prior knowledge and low self-regulation may not have actively processed the information offered through the learning aids, and hence did not benefit from the additional support offered. The use of aids by low prior knowledge learners and low self-regulators in the embedded condition may have been too superficial to have a beneficial effect compared to the segregated aidscondition.

Overall, it seems that our expectations with respect to the interaction between prior knowledge and the integration of learning aids on the one hand, and between self-regulation and the integration of learning aids on the other, could not be confirmed. The only two-way interaction that was identified was between prior knowledge and self-regulation on 
learning gains. However, indications that some compensation mechanisms between prior knowledge and self-regulation play a role were found.

The implications of this research for designing learning environments seem to be that a learning environment with segregated aids is the best option in cases of learners with high prior knowledge and low self-regulation skills. Similarly, for those learners with high self-regulation skills and low prior knowledge, segregated learning aids should be advocated. For students with high self-regulation and high prior knowledge segregation does not seem to matter. Hence, one could argue that segregating aids is, overall, the best solution from an instructional design perspective. However, for the group that is probably most in need of learning aids, namely learners with low prior knowledge and low self-regulation, the present study could not give a clear answer. It seems that simply providing learning aids is not sufficient. One could argue for the provision of additional training on the use of learning aids, as, for instance, studied by Gräsel, Fischer and Mandl (2000) or the provision of additional advice on the use of learning aids (e.g., Clarebout\& Elen, 2008), but also these studies generated mixed results.

Third, the generalizability is limited to learning environments in which only one type of learning aid is provided. It may be that the interplay between prior knowledge, self-regulation and integration of learning aids may be different when learners are confronted with a different type of learning aid, or with a combination of different types of learning aids. Additionally, we cannot assume these results to also be applicable to highly complex learning environments with high cognitive demands. Nevertheless, the study does provide some guidance for designing relatively 'simple' learning environments.

Although some implications are drawn from this study, some methodological issues cannot be ignored. First, looking at the learning gains, it seems that the experimental learning environment showed a ceiling effect for high prior knowledge learners. Second, in this study three aids were included, all three with almost identical content, and guiding learners at the same level. It could be argued that ideally the support should have gradually been withdrawn. Third, the rather limited number of participants does not allow for a grounded generalization.

A number of criticisms have been raised with regard to measuring self-regulation with surveys. The authors do acknowledge these critiques, but hence it is remarkable that even what people claim they do in order to regulate their learning influences their learning outcomes and interacts with prior knowledge. We cannot claim that we actually measured learners' self-regulation skills, nor are we sure that what students indicate they do corresponds to what they actually do, but apparently their intentions are predictive for their learning gains.

Given the compensation mechanisms that apparently operate between self-regulation and prior knowledge, it may be that, in future research, learner profiles should be viewed as independent variables, rather than specific isolated learner characteristics.However, this does not imply that these learner characteristics cannot be disentangled. This study showed that not only do prior knowledge and self-regulation compensate for one another, but also that they are clearly two distinguishable concepts that each influence in their own right learners' behaviour in a learning environment. 


\section{References}

Aleven, V., Stahl, E., Schworm, S., Fischer, F., \& Wallace, R. (2003). Help seeking and help design in interactive learning environments. Review of Educational Research, 73, 277-320.

Azevedo, R., \& Jacobson, M. J. (2008). Advances in scaffolding learning with hypertext and hypermedia: A summary. Educational Technology Research and Development, 56(1), 93-100.doi:10.1007/s11423-007-9064-3, http://dx.doi.org/10.1007/s11423-007-9064-3.

Clarebout, G., \& Elen, J. (2006). Tool use in computer-based learning environments: Towards a research framework. Computers in Human Behavior, 22(3), 389-411.doi:10.1016/j.chb.2004.09.007, http://dx.doi.org/10.1016/j.chb.2004.09.007.

Clarebout, G., \& Elen, J. (2008). Advice on tool use in open learning environments. Journal of Educational Multimedia and Hypermedia, 17, 81-97.

Clarebout, G., \& Elen, J. (2009). Benefits of inserting support devices in electronic learning environments. Computers in Human Behavior, 24(4), 804-810. doi:10.1016/j.chb.2008.07.004, http://dx.doi.org/10.1016/j.chb.2008.07.004.

Clarebout, G., Horz, H., Schnotz, W., \& Elen, J. (2010). Self-Regulation and the embedding of support devices in learning environments. Educational Technology Research and Development, 58(5), 573-587. doi:10.1007/s11423-009-9147-4, http://dx.doi.org/10.1007/s11423-009-9147-4.

Clark, R. E. (1990). When teaching kills learning: Research on mathetmathantics. In H. Mandl, E. De Corte, N.Bennett, \& H. F. Friedrich (Eds.), European research in an international context: Volume 2. Learning and Instruction (pp 1-22). Oxford, NY: Pergamon Press.

Elen, J., \&Clarebout, G. (2006). The use of instructional interventions: Lean learning environments as a solution for a design problem. In J. Elen \& R. Clark (Eds.), Handling complexity in learning environments: Theory and research. Advances in learning and instruction (pp. 185-200). Amsterdam: Elsevier.

Fraenkel, J. R., \&Wallen, N. E. (2003). How to design and evaluate research in education (5 ${ }^{\text {th }}$ ed.). New York: McGraw-Hill inc.

Gräsel, C., Fischer, F., \&Mandl. H. (2000). The use of additional information in problem-oriented learning environments. Learning Environment Research, 3, 287-325.

Greene, J. A., \&Azevedo, R. (2007, April). A macro-level analysis of SRL processes and their relations to the development of sophisticated mental models. Paper presented at the annual meeting of the American Educational Research Association, Chicago, IL.

Greene, B. A., \& Land, S. M. (2000). A qualitative analysis of scaffolding use in a resource-based learning environment involving the world wide web. Journal of Educational Computing Research, 23, 151-179.

Gurlitt, J., \&Renkl, A. (2008). Are high-coherent concept maps better for prior knowledge activation? Differential effects of concept mapping tasks on high school vs. university students. Journal of Computer Assisted learning, 24, 407-419.doi:10.1111/j.1365-2729.2008.00277, http://dx.doi.org/10.1111/j.1365-2729.2008.00277.

Hill, J. R., \&Hannafin, M. J. (2001). Teaching and learning in digital environments: The resurgence of resource-based learning. Educational Technology Research and Development, 45(1), 65-94.

Horz, H., Winter, C., \& Fries, S. (2009). Differential benefits of situated prompts on learning behaviour in authentic simulations. Computers in Human Behavior, 25(4),818-828. doi:10.1016/j.chb.2008.07.001, http://dx.doi.org/10.1016/j.chb.2008.07.001.

Kalyuga, S., Chandler, P., \&Sweller, J. (2000). Incorporating learner experience into the design of multimedia instruction. Journal of Educational Psychology, 92, 126-136.

Land, S. M. (2000). Cognitive requirements for learning with open-learning environments. Educational Technology Research and Development, 48(3), 61-78.

Martens, R. L., Valcke, M. M., \&Portier, S. J. (1997). Interactive learning environments to support independent learning: The impact of discernability of embedded support devices. Computers in Education, 28, $185-197$.

McNamara, D.S., Kintsch, E., Butler-Songer, N., \& Kintsch, W. (1996). Are good texts always better? Interactions of text coherence, background knowledge, and levels of understanding in learning from text. Cognition and Instruction, 14(1), 1-43. 
Narciss, S., Proske, A., \&Koerndle, H. (2007). Promoting self-regulated learning in web-based learning environments. Computers in Human Behavior, 23, 1126-1144.doi:10.1016/j.chb.2006.10.006, http://dx.doi.org/10.1016/j.chb.2006.10.006.

Nederkoorn, C., Guerrieri, R., \& Jansen, A. (2006). Leven in Luilekkerland [Living in wonderland]. De Psycholoog, 41(1), 10-16.

Perkins, D. (1985). The fingertip effect: How information-processing technology shapes thinking. Educational Researcher, 14, 11-17.

Potelle, H., \&Rouet, J-F. (2003). Effects of content representation and readers' prior knowledge on comprehension of hypertext. International Journal of Human-Computer Studies, 58, 327-345.

Schnotz, W., \&Heiss, A. (2009). Semantic scaffolds in hypermedia learning environments. Computers in Human Behavior, 25, 371-380. doi:10.1016/j.chb.2008.12.016

Shapiro, A. M. (2008). Hypermedia design as learner scaffolding. Educational Technology Research and Development, 56(1), 29-44.doi:10.1007/s11423-007-9063-4, http://dx.doi.org/10.1007/s11423-007-9063-4.

Wild, K.-P. (2000). Lernstrategien im Studium. Strukturen und Bedingungen [Learning Strategie in Academic Studies Structures an Conditions]. Münster: Waxmann.

Wild, K.-P. \&Schiefele, U. (1994). Lernstrategien im Studium. Ergebnisse zur Faktorenstruktur und Reliabilität eines neuen Fragebogens [Learning strategies in academicstudies. Results about factor structure and reliability of a new questionnaire]. Zeitschrift für Differentielle und Diagnostische Psychologie, 15, 185-200.

Williams, M. D. (1996). Learner-controlandinstructionaltechnology. In D. H. Jonassen (Ed.), Handbook of research for educational communications and technology (pp. 957-983). New York: Macmillian Library.

Winne, P. H.,\& Jamieson-Noel, D. (2002). Exploring students' calibration of self-reports about study tactics and achievement.Contemporary Educational Psychology, 27, 551-572.

Winters, F. I., Greene, J. A., \&Costich, c. A. (2008). Self-regulation of learning within computer-based learning environments: A critical analysis. Educational Psychology Review, 20, 429-444.

Table 1. Means for the retrieved main effects

\begin{tabular}{|l|c|c|}
\hline & Mean (sd)/Low & Mean (sd)/High \\
\hline Prior knowledge & $2.48(2.93)$ & $.94(3.26)$ \\
\hline Self-regulation & $1.95(2.50)$ & $1.74(3.51)$ \\
\hline & SA-condition & EA-condition \\
\hline Condition & $2.13(2.81)$ & $1.52(3.47)$ \\
\hline
\end{tabular}




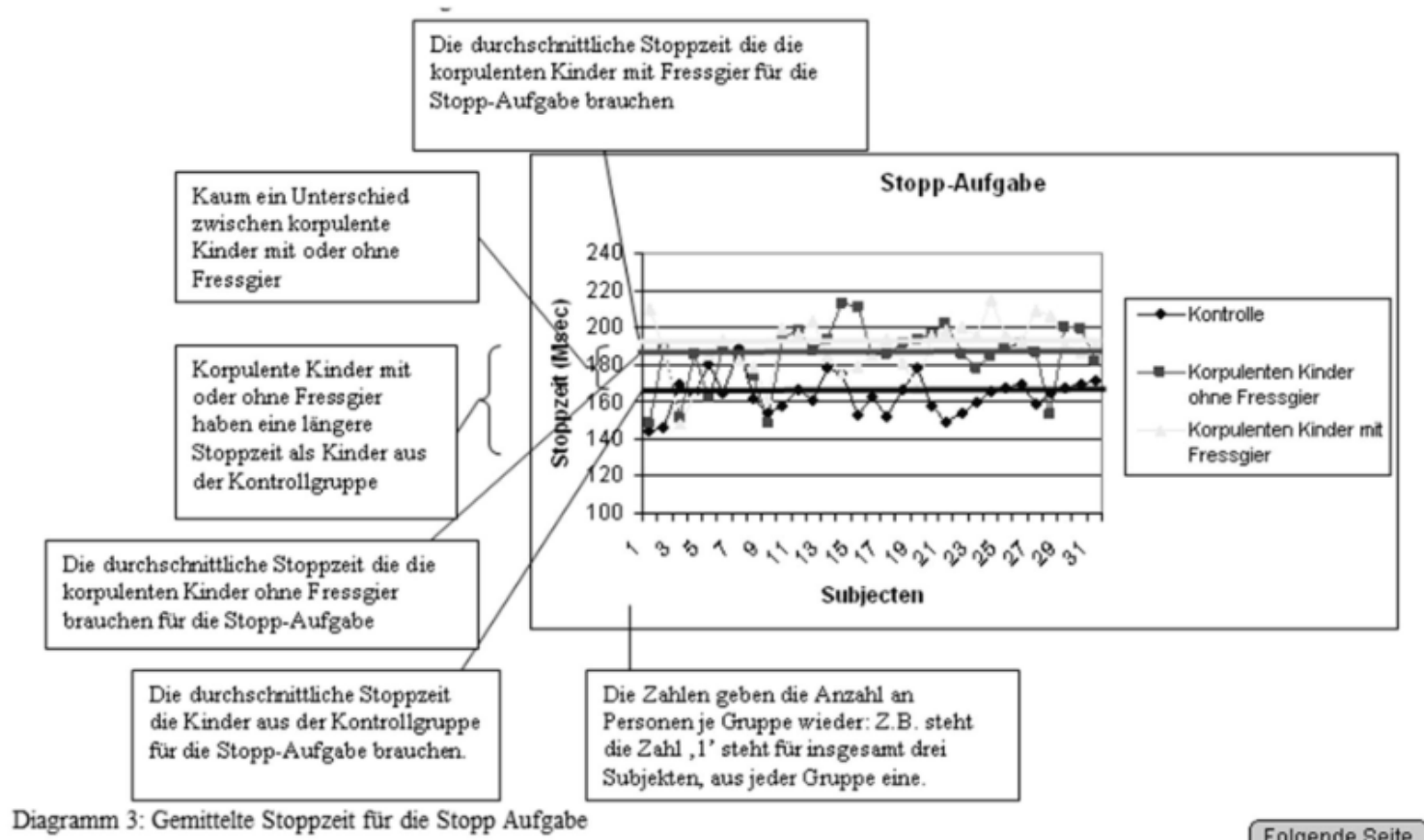

Figure1. Screen dump of the learning aid

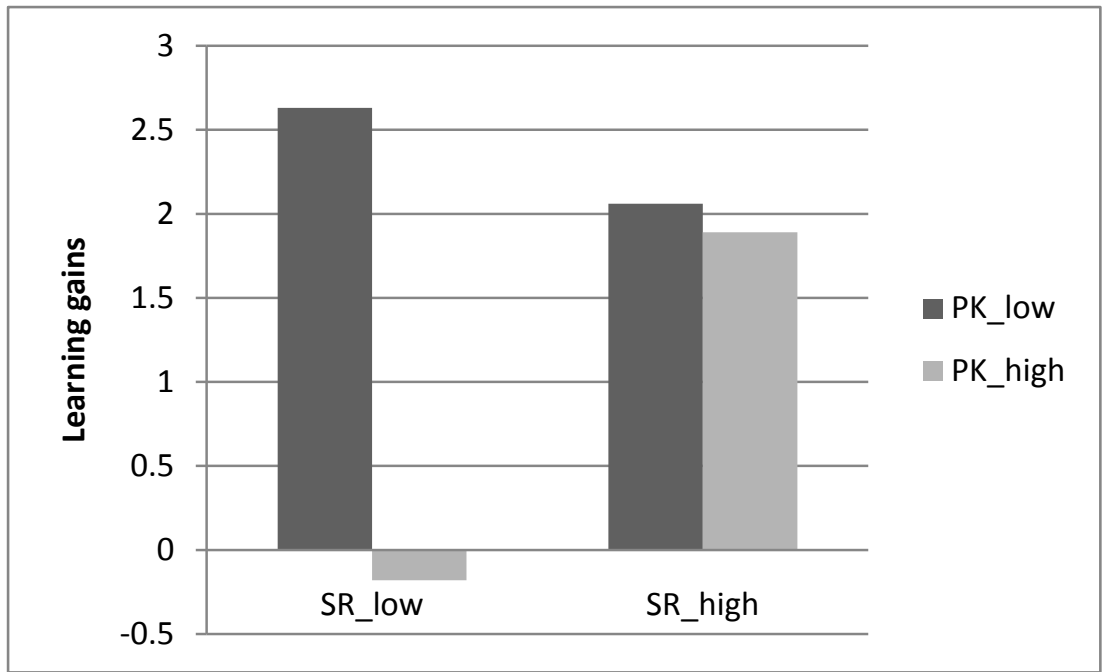

Figure 2. Interaction effect between prior knowledge and self-regulation on learning gains 


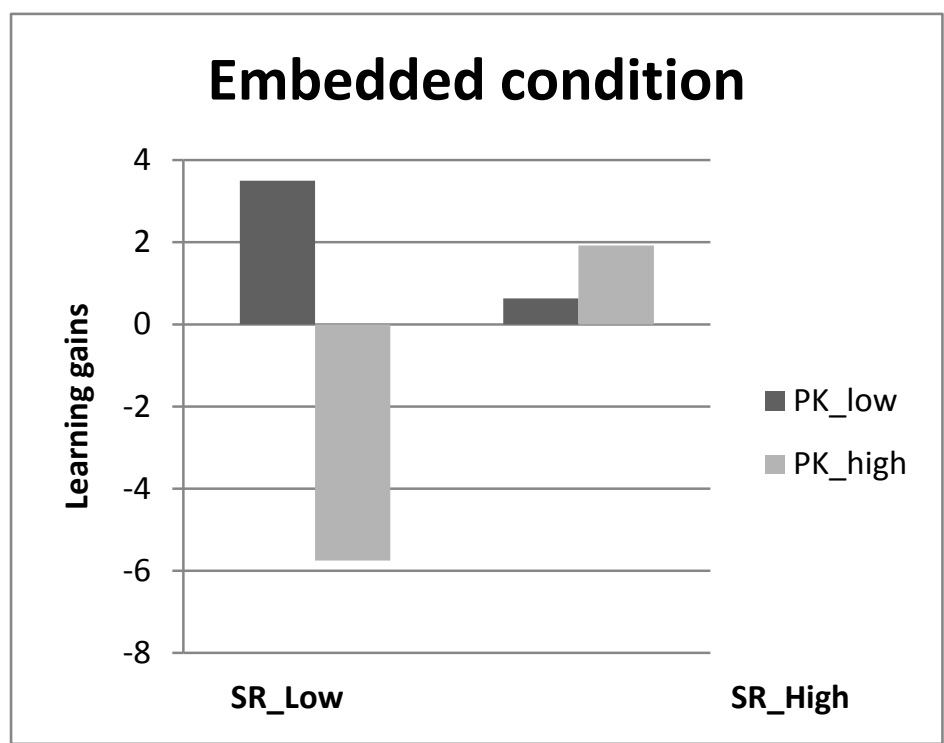

Figure 3. Interaction effect between prior knowledge, self- regulation on learning gains in the embedded condition

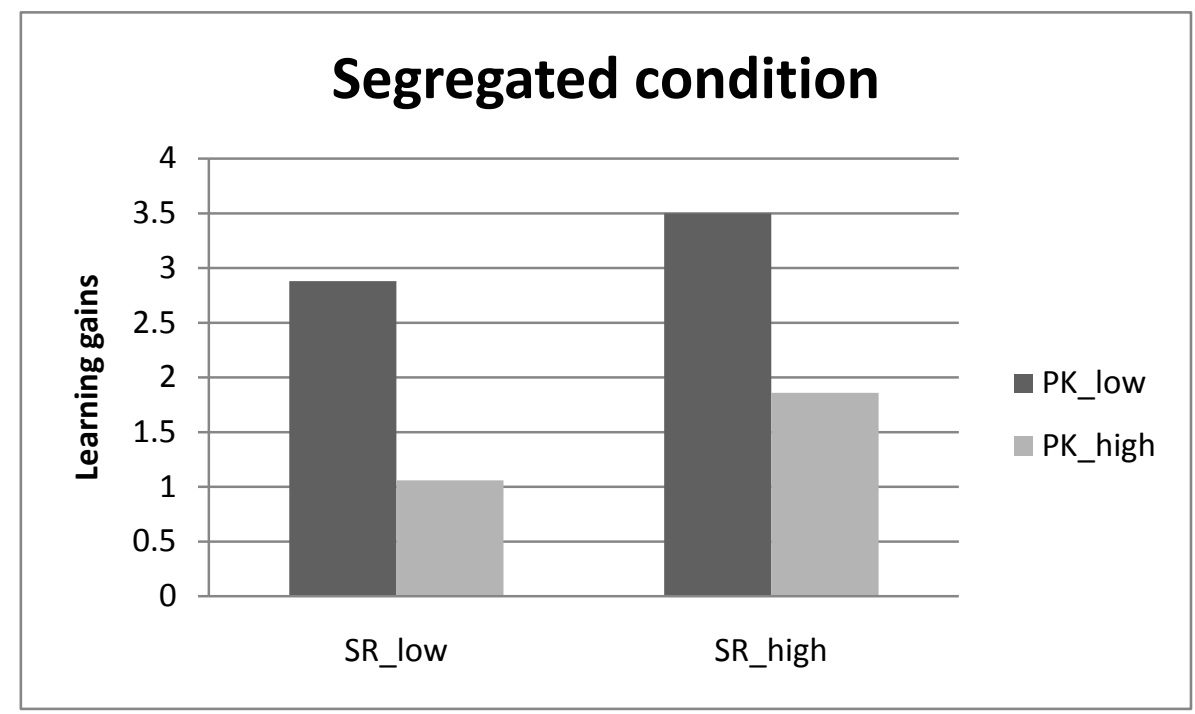

Figure 4. Interaction effect between prior knowledge, self- regulation on learning gains in the segregated condition 